\title{
PERANCANGAN KANTOR SEWA DENGAN PENDEKATAN ARSITEKTUR BIOKLIMATIK
}

\author{
Supriatna, Rita Laksmitasari, Ratu Arum \\ Program Studi Arsitektur \\ Fakultas Teknik, Matematika dan Ilmu Pengetahuan Alam \\ Universitas Indraprasta PGRI \\ priatna89ars@gmail.com
}

\begin{abstract}
Abstrak
Jakarta merupakan kota tujuan utama penyelenggaraan bisnis dan merupakan barometer indikator pembangunan Indonesia. Perkembangan bisnis di Jakarta akan berdampak pada bertambahnya kebutuhan dan pemasaran ruang perkantoran, karena pelaku bisnis akan membutuhkan ruang baru untuk bisnis atau ruang yang lebih besar untuk perkembangan bisnisnya. Kantor sewa cendrung dipilih oleh pelaku bisnis karena perusahaan dapat memiliki ruang perkantoran dengan beragam fasilitas tertentu dilokasi yang cendrung strategis sesuai dengan modal yang dimiliki dan kebutuhan besaran ruang. Akan tetapi permasalahan yang muncul dari pembangunan kantor sewa yaitu memiliki kenyaman thermal yang rendah akibat paparan radiasi matahari. Konsep arsitektur bioklimatik merupakan konsep arsitektural yang mampu menjawab permasalahan iklim dengan sadar akan potensi sumber daya alam seperti cahaya matahari, angin dan air hujan. Hasil yang diharapkan adalah desain yang mampu menerapkan konsep respon terhadap iklim pada tapak dan bangunan melalui orientasi bangunan, bukaan, dan penggunaan shading untuk fasad
\end{abstract}

Kata Kunci: jakarta, kantor sewa, bioklimatik

\begin{abstract}
Jakarta is the city's main business destination and a barometer of Indonesia's development indicators. Business development in Jakarta will have an impact on the increasing needs and marketing of office space, because business people will need new space for business or larger space for business development. Rental office tends to be chosen by the business because the company can have office space with a variety of certain facilities in the location that tends strategically in accordance with the owned capital and space needs. However, problems arising from the construction of rental offices that have low thermal comfort due to exposure to solar radiation. The concept of bioclimatic architecture is an architectural concept that is able to answer climate problems with the conscious of the potential of natural resources such as sunlight, wind and rain water. Expected results are designs that are able to apply climate-response concepts on the site and building through building orientation, aperture, and the use of shading for facades
\end{abstract}

Keywords: jakarta, rental office, bioklimatik 


\section{PENDAHULUAN}

\section{Latar Belakang}

Perkembangan bisnis di Jakarta akan berdampak pada bertambahnya kebutuhan dan pemasaran ruang perkantoran, karena pelaku bisnis akan membutuhkan ruang baru untuk bisnis baru atau ruang yang lebih besar untuk perkembangan bisnisnya. Jakarta sebagai kota besar tahun kedepan akan berkembang menjadi sebuah megapolitan. Jakarta bagaikan magnet yang selalu menjadi daya tarik bagi orang-orang dan segala aktivitas perekonomian. Seiring dengan perkembangan zaman yang memungkinkan peran swasta dalam pembangunan Jakarta, membuat Jakarta tumbuh sangat cepat. Melihat perkembangan kebutuhan masyarakat, maka sangat diperlukan bangunan sebagai sarana dan prasarana untuk menunjang kebutuhan-kebutuhan tersebut. Namun mengingat mahalnya harga lahan yang disebabkan oleh regulasi zoning kota yang telah diatur oleh pemerintah menurut fungsinya, mengakibatkan lahan menjadi terbatas, sehingga pemenuhan kebutuhan sebagai sarana dan prasarana tersebut tidak mungkin dibangun di sembarang tempat melainkan harus dibangun pada lahan yang sesuai dengan regulasi zoning kotanya. Kondisi tersebut memicu perkembangan bangunan secara vertikal sebagai upaya pemaksimalan ruang dalam keterbatasan lahan. Tren ini juga mewarnai perkembangan ruangruang usaha maupun perkantoran. Pemilihan lokasi di Jakarta setatan, memiliki beberapa faktor yaitu tingginya kegiatan ekonomi, tingginya harga lahan. Kecenderungan yang sedang berkembang saat ini adalah ruang perkantoran dengan sistem sewa atau kantor sewa. Kantor sewa yang ada cenderung dibangun dalam sistem bangunan tinggi agar efisien dan efektif terhadap pemanfaatan lahan.
Kantor sewa yang akan dibangun adalah kantor sewa dengan desain arsitektur bioklimatik yang merupakan desain pasif dan minim energi dengan pemanfaatan sumber daya alam seperti cahaya matahari, angin dan suhu setempat sangat cocok untuk diterapkan.

\section{TINJAUAN PUSTAKA}

\section{Pengertian kantor sewa}

Menurut Kamus Besar Bahasa Indonesia kata sewa adalah pemakaian sesuatu dengan membayar uang.

Menurut Hunt, W.D. dalam Marlina 2008, kantor sewa adalah suatu bangunan yang mewadahi transaksi bisnis dan pelayanan secara profesional.

Balai (gedung, rumah, ruang) tempat mengurus suatu pekerjaan (perusahaan, dan sebagainya) (Departemen Pendidikan dan Kebudayaan R.I., 1988).

Suatu wadah untuk menampung kegiatan administrasi (Poerwadarminto, 1976).

\section{Pengertian arsitektur bioklimatok}

Arsitektur bioklimatik adalah suatu pendekatan arsitektur yang mengarahkan arsitek untuk mendapatkan penyelesaian desain dengan memperhatikan hubungan antara bentuk arsitektur dengan memperhatikan lingkungan setempat dan memecahkan masalah lingkungannya dalam kaitan iklim dengan menerapkannya pada elemen bangunan. Pada akhirnya bentuk arsitektur yang dihasilkan juga dipengaruhi oleh budaya setempat, dan hal ini akan berpengaruh pada ekspresi arsitektur yang akan ditampilkan dari suatu bangunan (Yeang, 1996)

\section{Prinsip desain arsitektur bioklimatik}

Faktor yang mempengaruhi arsitektur bioklimatik menurut pendapat Yeang (1994) adalah : 
1. Meminimalkan ketergantungan pada sumber energi yang tak dapat diperbaharui.

2. Penghematan energi dari segi bentuk bangunan, penempatan bangunan dan pemilihan material.

3. Mengikuti pengaruh dari budaya setempat.

\section{METODE PERANCANGAN}

\section{Proses Pengumpulan Data}

Data Primer

Data yang diperoleh dari pengamatan secara langsung dengan orang-orang yang berkecimpung di dalamnya. Dalam proses ini penulis melakukan beberapa metode, diantaranya sebagai breikut :

1. Observasi lapangan

Observasi lapangan dilakukan pada lokasi tapak yaitu di jalan Prof. Dr. Satrio kuningan Jakarta Selatan. Keuntungan metode ini dapat merasakan langsung kondisi dan suasana dilapangan, sehingga dapat membantu dala proses perancangan. Berdasarkan hasil pengamatan diperoleh beberapa data di antaranya :

a. Ukuran tapak.

b. Kondisi kontur tapak.

c. Kondisi vegetasi dilokasi tapak.

d. Kondisi sistem drainase, listrik dan telfon di lokasi tapak.

e. Batas-batas yang mengelilingi tapak.

f. Kondisi umum sosial masyarakat disekitar tapak.

g. Kondisi umum sitem transportasi dan lebar jalan.

h. Suasana tapak yang meliputi iklim, angin, topografi tanah

i. serta data-data yang lain yang ada di lokasi tapak.

2. Wawancara

Wawancara dilakukan untuk mendapatkan data-data yang lebih detail yang dibutuhkan mengenai kebutuhan ruang, aktivitas pemakai, serta opini tentang segala sesuatu yang berhubungan dengan proses perencanaan kantor sewa.

3. Dokumentasi

Dokumentasi merupakan metode yang melingkupi proses observasi dan wawancara yang sudah dilakukan. Dalam hal ini dokumentasi yang dihasilkan berupa foto. Pada perancangan kantor sewa di Jakarta Selatan, foto tapak yang dihasilkan meliputi foto kondisi eksisting di tapak dan sekitarnya serta foto suasana kawasan.

\section{Tinjauan Proyek Sejenis}

Di lakukan untuk mendapatkan data terkait dengan objek dan tema perancangan. Studi ini dilakukan untuk bagaimana penerapan perancangan objek pada bangunan yang telah ada. Metode ini bisa dilakukan dengan pengambilan unsur-unsur perancangan yang bemilai positif dalam objek tinjauan dan memasukanya dalam desain rancangan baru yang direncanakan.

\section{Data Sekunder}

Data sekunder yaitu data atau informasi yang tidak berkaitan secara langsung dengan obyek perancangan tetapi sangat mendukung program perancangan kantor sewa. Data ini di dapat dari studi literatur atau sumber tertulis yang berhubungan dengan perancangan. Studi-studi tersebut diantaranya adalah sebagai berikut :

1. RDTRK yang berisi kondisi umum, rencana strategi pada kawasan yang berisi potensi dan peta kawasan.

2. Studi pustaka

3. Studi ini bertujuan untuk mendapatkan data dan teori yang terkait dengan perancangan, di antaranya adalah 


\section{a. Literatur tentang definisi dan fungsi bangunana kantor \\ b. Literatur tentang arsitektur \\ PEMBAHASAN DAN HASIL PERANCANGAN} prilaku

c. Serta literatur yang berasal dari data internet, buku dan majalah yang berisi hal-hal yang berhubungan dengan perancangan

\section{Studi Komparatif}

Studi komparatif ini adalah studi mengenai pola ruang, bentuk, tata atur

\section{Tinjauan Tapak}

Lokasi pembangunan kantor sewa berada dijalan Prof. Dr. Satrio Setiabudi Jakarta Selatan. Site ini dekat dengan kawasan mega kuningan, disekeliling tapak terdapat berbagai macam bangunan dengan fungsi yang berbeda-beda mulai dari komersial, hingga hunian. dan unsur-unsur yang berkaitan dengan objek.
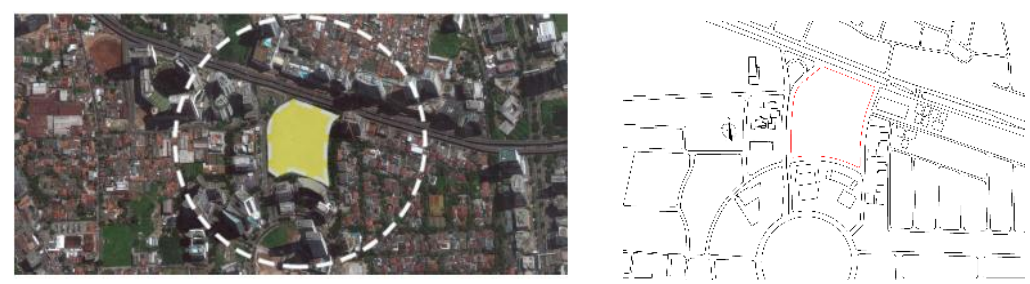

Gambar1. Lokasi dan layout tapak

\section{Analisis dan konsep matahari}

Dilakukan analisis cahaya matahari menggunakan sunpath untuk mengetahui arah datang matahari. Berdasarkan analisis sunpath pada tapak, dapat

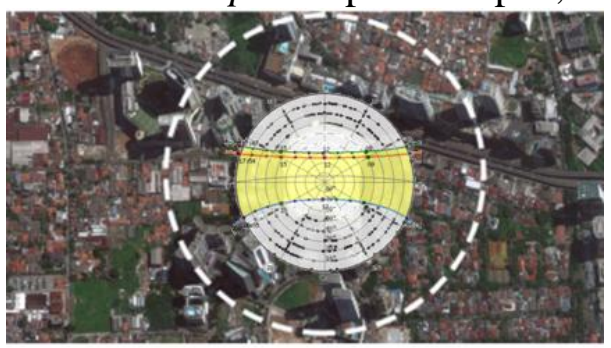

diperoleh konsep yang dilakukan kepada tapak yaitu massa bangunan yang luasan terkecil menghadap ke timur dan barat

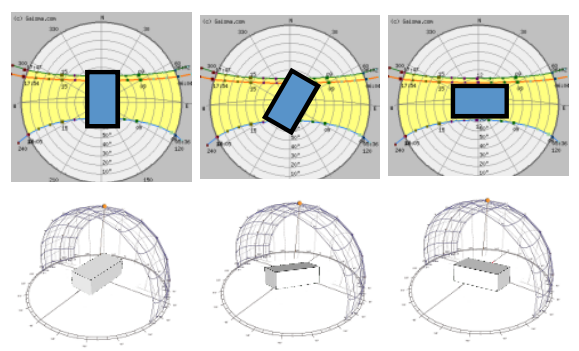

Gambar 2. Diagram sunpath dan konsep matahari

Untuk mengetahui arah orientasi terbaik perancangan kantor sewa ini dilakukan simulasi analisis optimum pembayangan pada bangunan untuk memastikan keuntungan yang diperoleh dari arah orientasi yang ditentukan. 


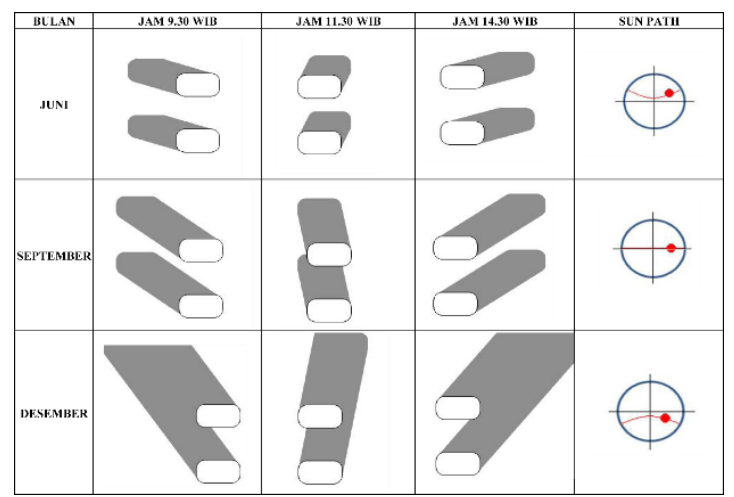

Gambar 3. Analisa optimum dan pembayangan pada bangunan

Dari hasil analisa maka sisi utara dan barat yg paling banyak mendapatkan panas matahari maka fasad bangunan sebelah timur dan barat diberikan shading vertical dan horizontal untuk menghalau panas matahari, sedangkan fasad sebelah utara dan selatan diberi shading vertikal
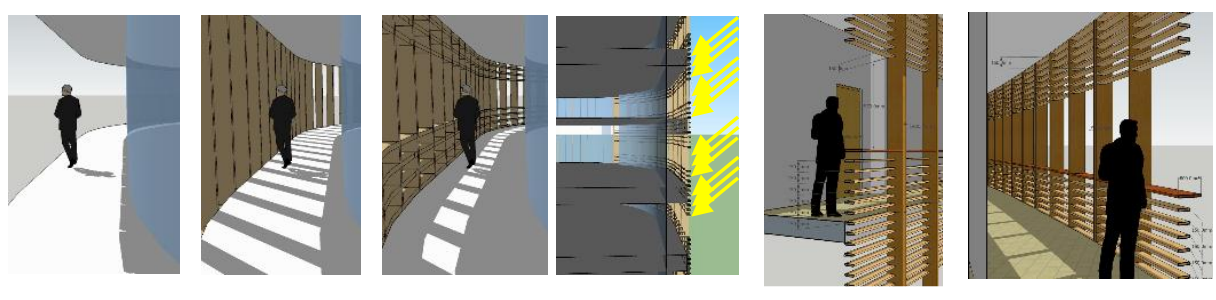

Gambar 4. Konsep fasad banguan

Konsep orientasi ini dipilih karena sisi timur dan barat yang banyak mendapatkan panas matahari, sehingga

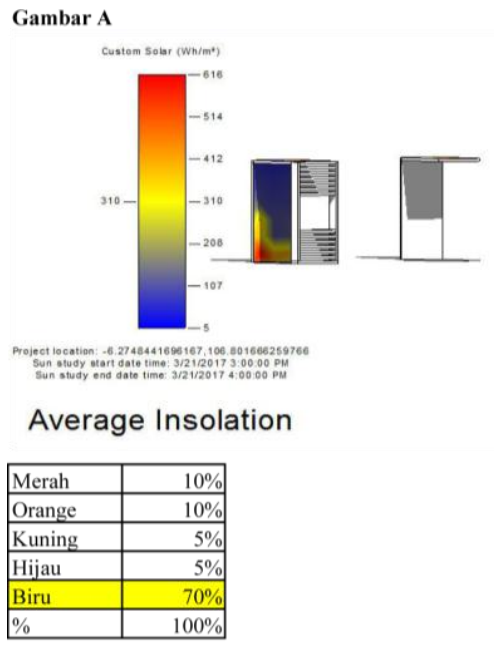

dilakukan simulasi sofware revit untuk memastikan keuntungan yang diperoleh dari arah orientasi yang ditentukan.

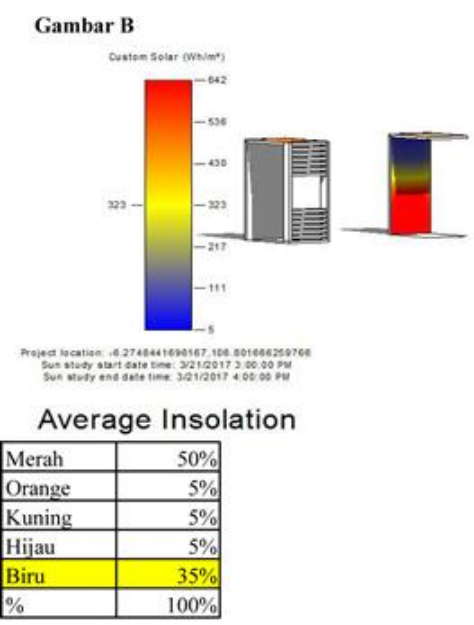

Gambar 5. Uji simulasi solar analisis

Dengan pendekatan solar analisis maka hasil pembayangan yang menggunakan shading pada gambar A sangat banyak sehingga bisa menekan panas matahari yang masuk sebesar $70 \%$. 


\section{Analisis dan konsep pemanfaatan air hujan}

Selain matahari hal yang perlu dicermati adalah curah hujan yang cukup tinggi. Untuk mengantisipasi hal tersebut maka perlu dibuat daerah-daerah resapan air dan tentunya didukung oleh system drainnase (pembuangan air hujan) yang baik, Selain itu air hujan dapat ditreatmen terlebih dahulu untuk kemudian ditampung didalam reservoir bawah yang kemudian dapat dimanfaatkan untuk keperluan penyiraman tanaman, membersihkan ruang ME/ jalan dan flushing toilet
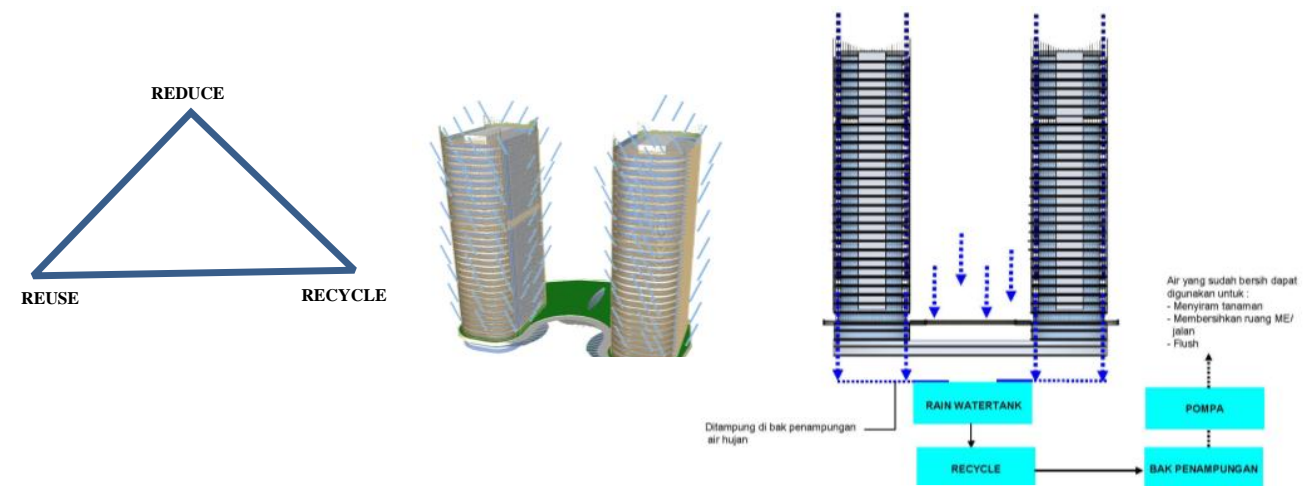

Gambar 6. Sistem pemanfaatan air hujan

Reduce : air hujan yg datang sebagian buang ke saluran yang baik (Drainase)

Reuse : menggunakan air hujan untuk dapat digunakan kembali setelah melalui beberapa proses seperti di treatmen terlebih dahulu

Recycle : setelah melalui beberapa proses air hujan dapat digunakan untuk keperluan penyiraman tanaman dan flushing toilet

\section{Analisis dan konsep angin}

Angin yang bergerak disebabkan gedung yang tinggi dapat dikontrol untuk meningkatkan atau mengurangi laju angin tersebut. Sebuah bangunan aerodinamis dapat mengatur laju kecepatan angin dengan mengubah pola pergerakan angin tersebut, dengan meneliti pola pergerakan angin tersebut dapat mengurangi tekanan angin pada bangunan Kwok Bailey, 1987.

Dengan menambahkan lagi perubahan pada setiap sudutnya maka bangunan ini mengikuti pola dan tekanan pergerakan angin, bangunan akan lebih adaptif dari tekanan angin pada bangunan.
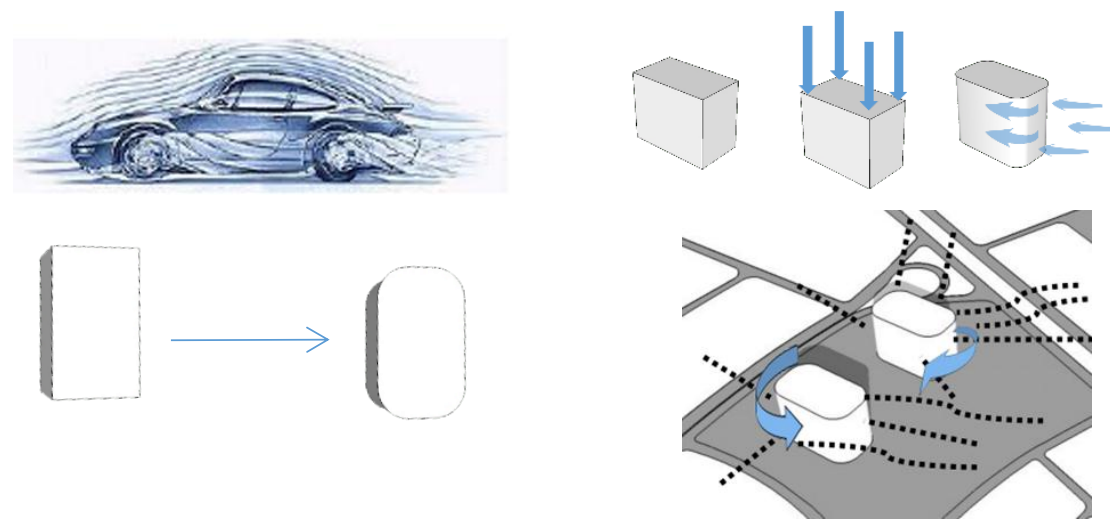

Gambar 7. Konsep aerodinamis 


\section{Konsep roof garden}

Selain sebagai penghubung bangunan roof garden difungsikan sebagai sarana untuk mengurangi beban panas dalam bangunan dan juga karbon dioksida pada lingkungan.
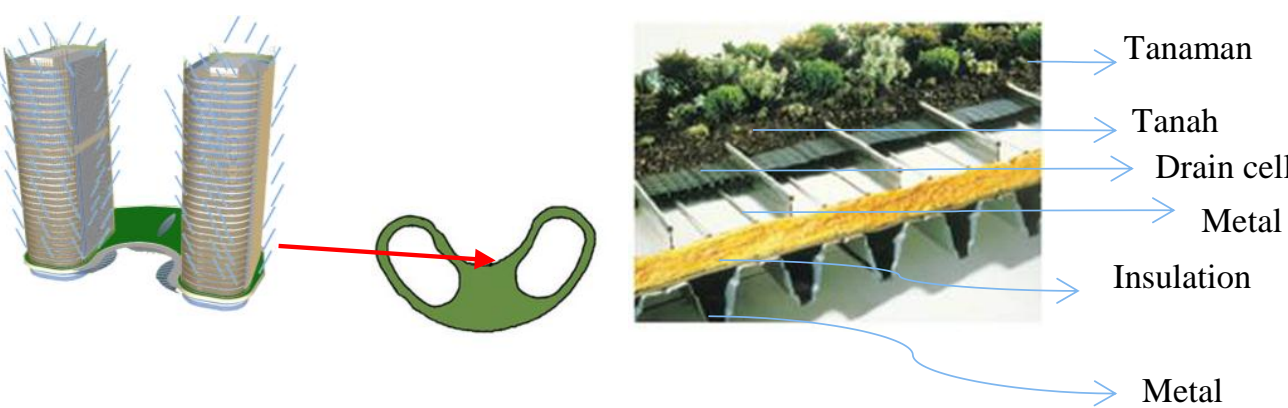

Gambar 8. Konsep roof garden

Desain

Bangunan kantor sewa ini merupakan bangunan 30 lantai termasuk 1 lantai refuge. Bentuk orientasi bangunan dibuat dari arah timur ke barat untuk mengurangi paparan sinar matahari secara langsung

$$
\begin{array}{ll} 
& \text { LEGEND : } \\
\text { 1. } & \text { ENTRANCE MOBIL } \\
\text { 2. } & \text { ENTRANCE KE 2 \& } \\
& \text { MOBIL SERVICE } \\
\text { 3. } & \text { ENTRANCE MOTOR } \\
\text { 4. } & \text { EXIT } \\
\text { 5. EXIT MOTOR } \\
\text { 6. EXIT } \\
\text { A. TOWER BANGUNAN } \\
\text { B. ROOF GARDEN } \\
\text { C. TAMAN } \\
\text { D. PARKIR } \\
\text { E. PEDESTRIAN }
\end{array}
$$

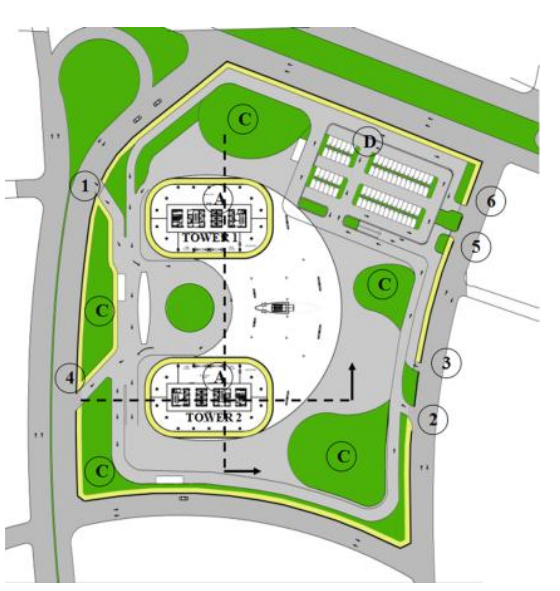

Gambar 9. Gambar layout plan

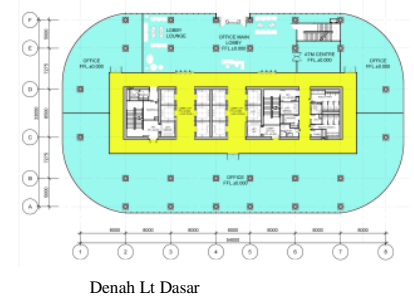

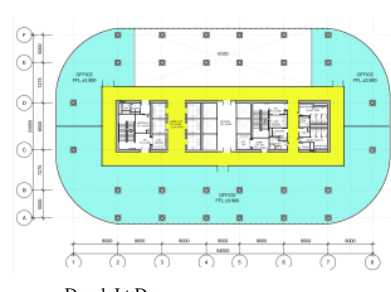

Denah Lt Dua

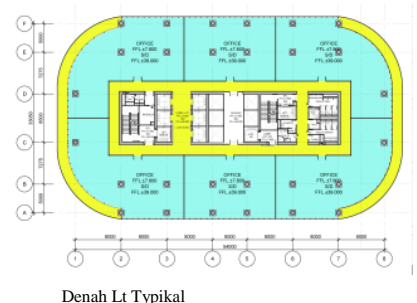

Denah Lt Typikal

Gambar 10. Gambar denah bangunan 


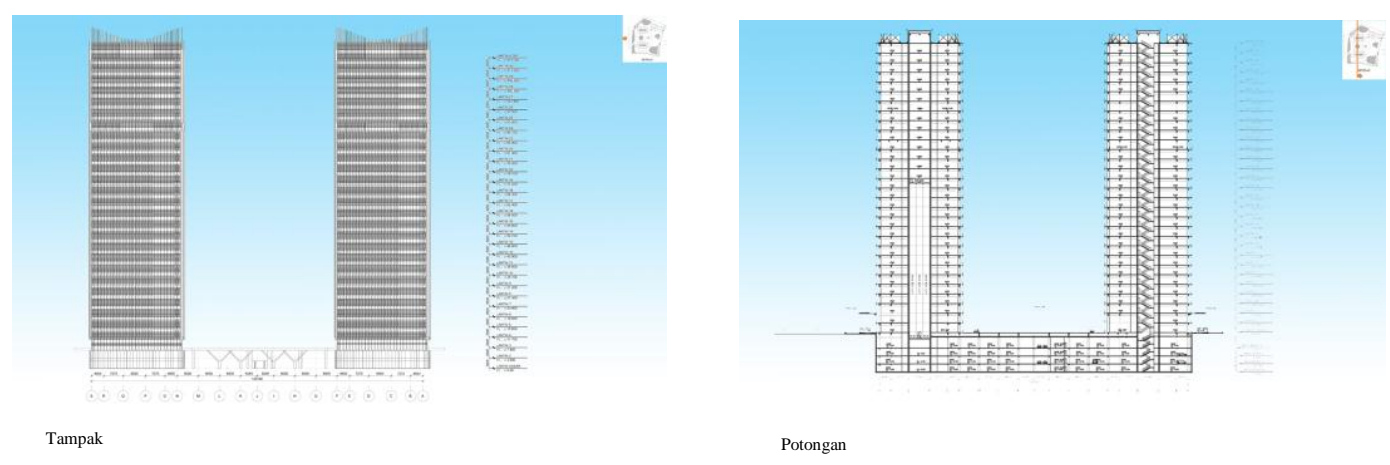

Gambar 11. Tampak \& potongan bangunan

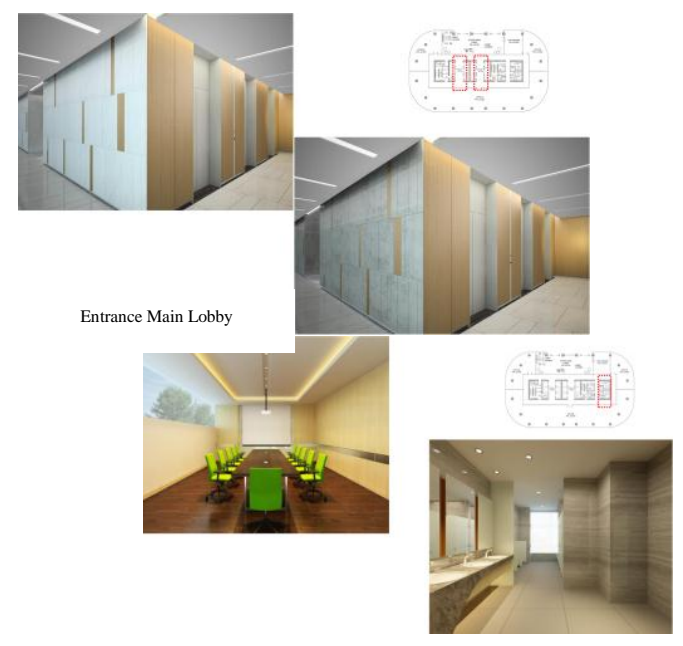

Ruang Rapat

Gambar 12. Interior bangunan

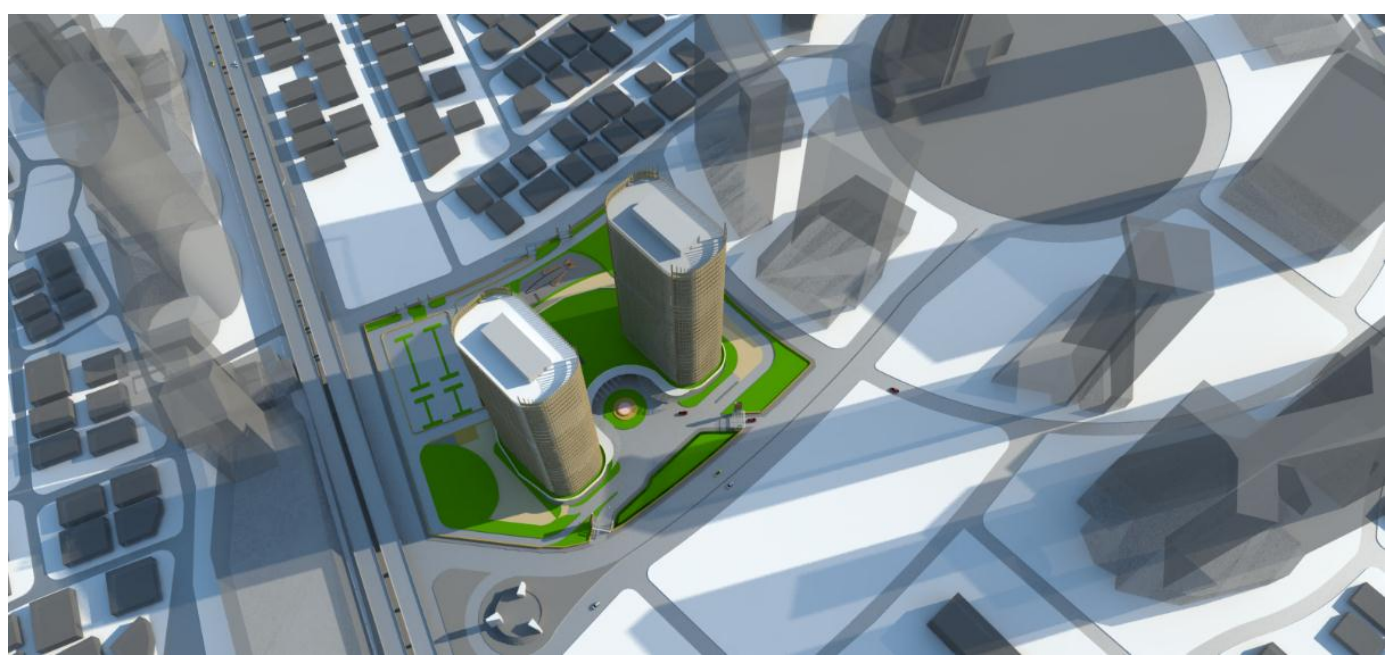

Gambar 13. Aerial view 

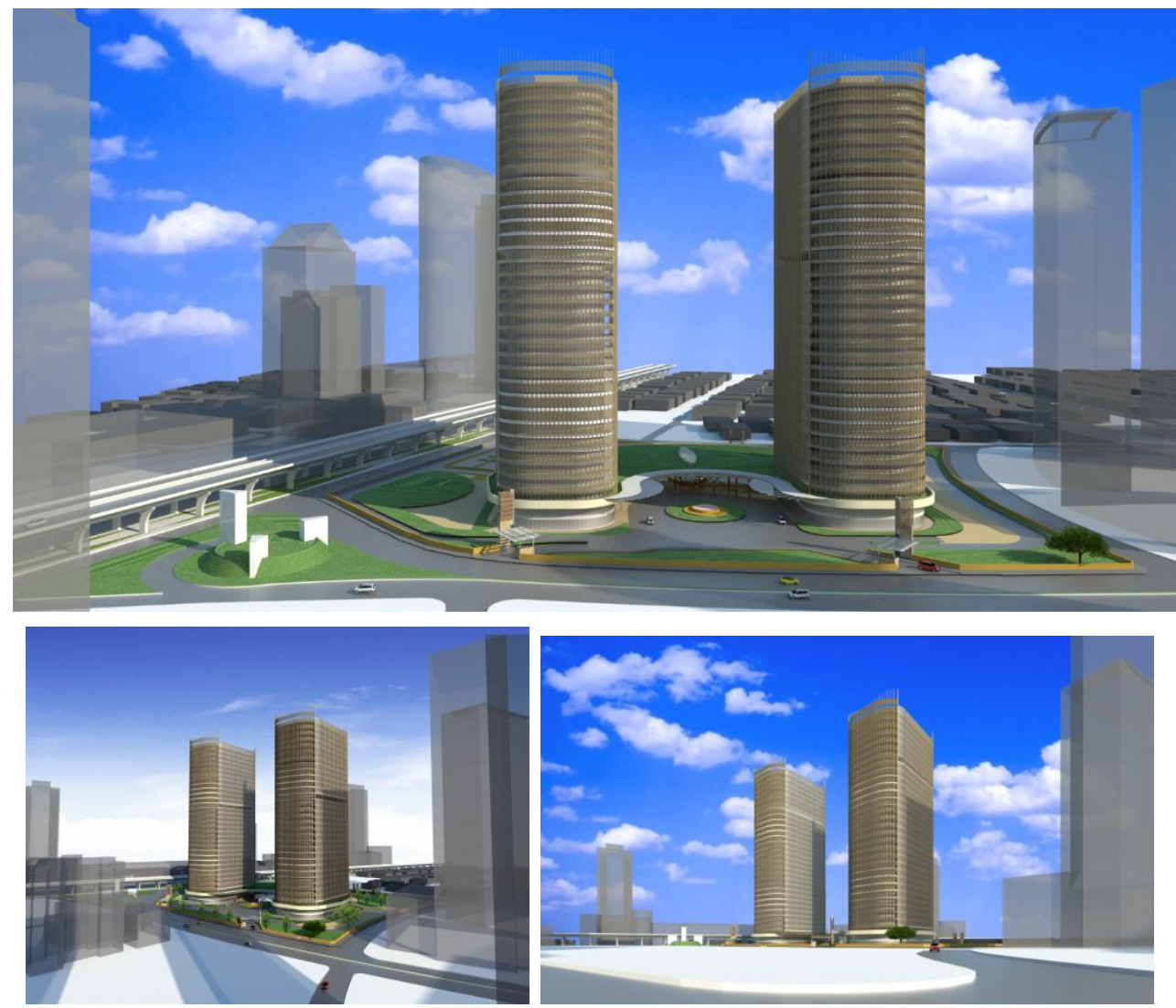

Gambar 14. Eksterior bangunan

\section{SIMPULAN}

Perancangan kantor sewa dengan pendekatan arsitektur bioklimatik merupakan salah satu cara untuk mengoptimalkan iklim yang ada pada tapak. Orientasi bangunan ini dilakukan untuk penentuan arah hadap bangunan terhadap kondisi eksiting tapak terkait arah matahari, tujuan utamanya yaitu mengarahkan bangunan agar menghindari panas matahari langsung sehingga luasan bangunan yang terkecil menghadap ke timur dan barat sedangkan untuk menghalau panas matahari fasad bangunan menggunakan shading vertikal dan horisontal. Parameter bioklimatik yang digunakan pada kantor sewa ini terbagi menjadi empat jenis yaitu orientasi ter- hadap matahari, pemanfaatan air hujan, respon terhadap angin dan roof garden.

\section{DAFTAR PUSTAKA}

De Chaira, J. and Lee E, K. (1975). Standar Perencanaan Tapak. Jakarta: Erlangga.

Kamus Besar Bahasa Indonesia, (1988). Jakarta : Dep. P\&K,

Yeang, K., (1994). "Bioclimatic Skyscrapers", London, Artemis London Ltd. (1996). "The Skyscraper Bioclimatically Considered", London, Academy 